\title{
Simulation on neonatal stabilization and transport
}

\author{
Armando Cuttano ${ }^{1 *}$, Rosa T Scaramuzzo ${ }^{1}$, Francesca Moscuzza', Davide Panizza ${ }^{2}$, Massimiliano Ciantelli ${ }^{1}$, \\ Marco Vuerich ${ }^{1}$, Emilio Sigali ${ }^{1}$, Antonio Boldrini ${ }^{1,2,3}$ \\ From XXI Congress of the Italian Society of Neonatology \\ Palermo, Italy. 24-26 September 2015
}

Legal problems are more numbered even in Neonatology. Hospital policy should establish strategies to limit systematic, environmental and human errors, including solutions to optimize organization and increase knowledge [1].Staff retraining by means of simulation could be a precious instrument.

Simulation works through mechanisms that are proper of our brain for decision-making (i.e. simulated mind) [2]. The capacity of evaluating a situation earlier than it happens and so planning possible actions is the so called anticipatory simulation [3]. Physiological basis of simulation effectiveness are deeply related to mirror neurons [4]. Simulation emphasizes the so called "deutero-learning", i.e. the context in which (proto-)learning processes occur: at the same time people are learning simple concepts, and also learning something about the world and about how things occur [5]. In sum, simulation maximises learning through the extraction of implicit rules, and putting specific bits of basic experiences in context to generalise them.

The aim of this lecture is to focus on methods of simulation on neonatal stabilization and transport (more than on medical procedures themselves).

Simulation retraining for medical (or nurse) staff should be based on the andragogic approach: adults are conscious of their own educational needs and focus their own attention on specific interests (related to daily practice) [6]. This methodological approach needs that teachers behave as peers towards learners, with empathy and a collaborative attitude.

A precious additive methodological element is fun: the serious medical game is the approach to optimize technical memories trough emotions [5].

\footnotetext{
*Correspondence: acuttano@gmail.com

'Centro di Formazione e Simulazione Neonatale "NINA", U.O. Neonatologia -

Azienda Ospedaliero Universitaria Pisana, Italy

Full list of author information is available at the end of the article
}

In our experience, materials for simulation are daily clinical devices and innovative stuff developed by a multidisciplinary collaboration [7]; we discuss published guidelines (e.g. STABLE Program) and participants' experiences.

As regards neonatal stabilization and transport, we perform: i) annual retraining sessions for all the operators in our Unit, ii) low and medium fidelity simulation sessions for nearby hospitals, iii) high fidelity sessions for colleagues working at geographically uncomfortable hospitals (i.e. island) and so needing for transport by helicopter, as a kind of "full scale CRM (Crisis Resources Management)".

In our opinion the traditional approach to teaching is inadequate for retraining of adult professionals. We propose simulation as the method to deepen knowledge, strengthen abilities and so optimize performances. Recording sessions and analysing them to discuss behaviours is a main instruments for debriefing. Every kind of support (e.g. e-learning platforms, papery stuff, pocket memory materials, etc) is admitted and should be creatively promoted.

\section{Authors' details}

'Centro di Formazione e Simulazione Neonatale "NINA", U.O. Neonatologia Azienda Ospedaliero Universitaria Pisana, Italy. ${ }^{2}$ Istituto di Scienze della Vita, Scuola Superiore Sant'Anna di Pisa, Italy. ${ }^{3}$ Università di Pisa, Italy.

\section{Published: 24 September 2015}

\section{References}

1. Committee on quality of health care in America: To err is human: building a safer health system. National Academy of Sciences 1999.

2. Shanton K, Goldman A: Simulation theory., DOl: 10.1002/wcs.33.

3. Broekens J, Kosters WA, Verbeek FJ: Anticipation, and Adaptation: AffectControlled Selection of Anticipatory Simulation in Artificial Adaptive Agents. Adaptive Behavior 2007, 15(4):397-422.

4. Caramazza A, Anzellotti S, Strnad L, Lingnau A: Embodied cognition and mirror neurons: a critical assessment. Annu Rev Neurosci 2014, 37:1-15. 
5. Doglio M: Imparare per ridere - Note in margine del pensiero di Gregory Bateson. Edizioni Change 2005.

6. Knowles M: The making of an adult educator: An autobiographical journey (Ed.). San Francisco, CA: Jossey-Bass; 1989.

7. Tognarelli S, Baldoli I, Scaramuzzo RT, Ciantelli M, Cecchi F, Gentile M, Laschi C, Sigali E, Menciassi A, Cuttano A: Development and validation of a sensorized neonatal intubation skill trainer for simulation based education enhancement. Int J Med Res Health Sci 2014, 3(4):833-839.

doi:10.1186/1824-7288-41-S1-A5

Cite this article as: Cuttano et al: Simulation on neonatal stabilization and transport. Italian Journal of Pediatrics 2015 41(Suppl 1):A5.

Submit your next manuscript to BioMed Central and take full advantage of:

- Convenient online submission

- Thorough peer review

- No space constraints or color figure charges

- Immediate publication on acceptance

- Inclusion in PubMed, CAS, Scopus and Google Scholar

- Research which is freely available for redistribution

Submit your manuscript at www.biomedcentral.com/submit
C Biomed Central 